\title{
AVALIAÇÃO FÍSICO-QUÍMICA E SENSORIAL DO IOGURTE NATURAL PRODUZIDO COM LEITE DE BÚFALA CONTENDO DIFERENTES NIVEIS DE GORDURA'
}

Otaviano Carneiro CUNHA NETO', Carlos Augusto Fernandes OLIVEIRA**, Ricardo Muta HOTTA', Paulo José Amaral SOBRAL

\begin{abstract}
RESUMO
A elaboração de iogurtes pode ser considerada uma excelente alternativa para a utilização industrial do leite de búfala. Entretanto, alguns problemas de aceitação por parte dos consumidores podem ocorrer devido ao elevado conteúdo de gordura do leite original. Este trabalho teve por objetivo avaliar algumas características do iogurte natural batido elaborado com leite de búfala com os seguintes teores de gordura: integral, 3,0\% (padronizado) e 0,5\% (desnatado). Os iogurtes foram embalados em frascos de polietileno de $1 \mathrm{~L}$ e estocados a $5^{\circ} \mathrm{C}$ por 30 dias. Amostras foram colhidas nos dias $1,15 \mathrm{e} 30$ e submetidas à análise de acidez, $\mathrm{pH}$, viscosidade e avaliação sensorial. Os valores de acidez e pH não apresentaram diferenças $(\mathrm{P}>0,05)$ entre os tratamentos, durante o período de estocagem. A viscosidade também não foi influenciada $(\mathrm{P}>0,05)$ pelos níveis de gordura nos dias 1,15 e 30 . O iogurte produzido com leite padronizado apresentou notas maiores $(\mathrm{P}<0,05)$ quanto ao sabor na análise sensorial nos dias 15 e 30 . Conclui-se que, o desnatamento do leite de búfala não altera as propriedades fisico-químicas estudadas no iogurte durante o armazenamento por 30 dias, e que o iogurte padronizado a 3,0\% de gordura apresenta uma melhor qualidade sensorial.

Palavras-chave: leite bubalino; leites fermentados; análise.
\end{abstract}

\section{SUMMARY}

PHYSICO-CHEMICAL AND SENSORY EVALUATION OF PLAIN YOGURT MANUFACTURED FROM BUFFALO MILK WITH DIFFERENT FAT CONTENT. Yogurt can be considered an excellent alternative for utilization of buffalo milk. However, consumers may have some acceptance problems in relation to buffalo yogurt because of the original high fat content of the milk. The aim of the present study was to evaluate some characteristics of stirred plain yogurt produced from buffalo milk with the following fat levels: whole milk, $3.0 \%$ (standardized) and $0.5 \%$ (skim). Yogurts were stored in $1 \mathrm{~L}$ polyethylene bottles at $5^{\circ} \mathrm{C}$ for 30 days. Samples were collected at 1,15 and 30 days of storage and submitted to the following analysis: acidity, $\mathrm{pH}$, viscosity and sensorial evaluation. Acidity and $\mathrm{pH}$ values showed no differences $(\mathrm{P}>0.05)$ among treatments during storage. Viscosity was not influenced $(\mathrm{P}>0.05)$ by fat content in yogurts on days 1,15 and 30 after manufacture. Standardized yogurt obtained higher scores $(P<0.05)$ for taste in sensorial analysis at 15 and 30 days storage. It is concluded that skimming of buffalo milk does not alter the studied physical and chemical properties of yogurt during storage for 30 days, and that standardized yogurt at $3.0 \%$ fat shows a better sensorial quality. Keywords: buffalo milk; fermented milks; analysis.

\section{INTRODUÇÃO}

A criação de búfalos para o fornecimento de leite vem se desenvolvendo de maneira acentuada no Brasil, sendo que diversos produtores têm demonstrado um crescente interesse pela produção leiteira com vistas, sobretudo, ao fornecimento de leite para elaboração de derivados [14]. Em vários países, o leite bubalino é utilizado para elaborar diferentes derivados lácteos, como alguns tipos de queijos, iogurtes e outros leites fermentados produzidos regionalmente, tais como dahi, khoa, kúselo mleko, natural yoch e zabady $[7,9]$.

A utilização do leite de búfala para a produção industrial de iogurtes tem sido pouco reportada na literatura. Todavia, os poucos resultados obtidos apontam o leite de búfala como uma possibilidade a ser explorada pela in-

Recebido para publicação em 17/11/2003. Aceito para publicação em 11/08/2005(001253).

Departamento de Engenharia de Alimentos, Faculdade de Zootecnia e Engenharia de Alimentos, Universidade de São Paulo. Endereço: Av. Duque de Caxias Norte 225. CEP: 13635-900, Pirassununga-SP, Brasil.E-mail: carlosaf@usp.br

A quem a correspondência deve ser enviada. dústria de laticinios, uma vez que a sua utilização proporciona um corpo e uma textura mais firme ao iogurte, quando comparado com o iogurte elaborado com leite bovino [12]. Este fato pode ser atribuído, em parte, aos maiores teores de gordura e proteína do leite bubalino, em relação ao leite de vaca [21].

As etapas de produção do iogurte incluem, de modo geral, verificação das características do leite original, padronização do teor de gordura, tratamento térmico, semeadura, incubação e embalagem do produto final [20]. Na elaboração de iogurte de leite de vaca, um elevado teor de sólidos totais (ST) no leite (entre 14-18\%) é desejável para proporcionar um produto com boa qualidade, o que, normalmente, requer a adição de leite em pó para fortificação do valor de ST [19].

O iogurte produzido com leite bubalino integral apresenta, após cerca de 15 dias de armazenamento a 7 C, valores de acidez variando entre 0,78 [22] e 1,21\% (expressa em g de ácido láctico/100g de iogurte) [17]. Para o iogurte obtido com leite bovino, SOUZA [19] considera o valor de acidez de $0,9 \%$ como essencial para o desenvolvimento do sabor e aroma peculiares ao iogurte. Com relação ao $\mathrm{pH}$ do iogurte produzido com leite de búfala integral, trabalhos anteriores apontam valores entre 4,03 [17] e 4,74 [22] após cerca de 15 dias de armazenamento a 7 C. De acordo com a legislação brasileira [4], o iogurte 
deve apresentar acidez entre 0,6 e 1,5\% e uma contagem minima de 10 unidades formadoras de colônias (UFC) de bactérias láticas por $\mathrm{mL}$ do produto.

São escassos os trabalhos que abordam a avaliação sensorial de iogurte produzido exclusivamente com leite de búfala, sendo que alguns estudos indicam uma menor aceitação do iogurte produzido com leite integral, em relação ao leite integral bovino [16,22]. Entretanto, CHAWLA $\&$ BALACHANDRAN [5] observaram que o iogurte de leite de búfala contendo $3,0 \%$ de gordura e $10 \%$ de sólidos não-gordurosos (SNG), apresentou bom desempenho na avaliação sensorial realizada por provadores treinados. Neste trabalho, os autores também observaram valores crescentes de viscosidade no iogurte contendo 9,0 a $15,0 \%$ de ST.

O objetivo do presente trabalho foi realizar a avaliação físico-química e sensorial do iogurte natural batido produzido com leite bubalino contendo três niveis de gordura (teor de gordura integral, padronizado a 3,0\% e desnatado a $0,5 \%$ ), durante 30 dias de armazenagem.

\section{2 - MATERIAL E MÉTODOS}

\section{1 - Obtenção do leite}

O leite utilizado no experimento foi proveniente de um único rebanho, obtido no período de abril a junho de 2002, através da ordenha manual de fêmeas bubalinas da raça Murrah, em condições higiênicas adequadas. Após a ordenha, o leite era imediatamente resfriado a $5{ }^{\circ} \mathrm{C}$ em tanque de expansão, transferido para latões de polipropileno previamente higienizados e transportados (durante cerca de 50 minutos) até o laticínio onde foram realizados os processamentos. O volume de leite utilizado em cada dia de processamento foi de 90L, divididos em 3 partes de 30L para constituição dos 3 tratamentos previstos no experimento.

\section{2 - Caracterização da matéria-prima}

Após a chegada no laticínio, o leite foi imediatamente homogeneizado por agitação manual com haste de aço inox para colheita de amostras, em triplicata, com vistas à realização das seguintes análises: $\mathrm{pH}$, acidez ( D), densidade, indice crioscópico (IC) e percentuais de gordura, proteina, ST e SNG [2].

\section{3 - Desnatamento e padronização do teor de gordura}

Cerca de 2/3 do volume de leite bubalino integral foi aquecido a $50^{\circ} \mathrm{C}$ e submetido à centrifugação em desnatadeira aberta (capacidade de $225 \mathrm{~L} / \mathrm{h}$ ) para a obtenção de leite desnatado e creme, com a finalidade de constituir o leite dos tratamentos previstos no experimento, ou seja, leite integral, leite padronizado a 3,0\% de gordura e leite desnatado a $0,5 \%$ de gordura.

A padronização do leite foi realizada através da mistura de leite integral e leite desnatado, fazendo-se o cál- culo das quantidades de cada um de acordo com SPREER [20], através da equação (1):

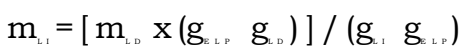

onde,

$\mathrm{m}_{\mathrm{t}}=$ peso do leite integral a ser adicionado $(\mathrm{em} \mathrm{kg})$;

$\mathrm{m}_{\mathrm{t}}=$ peso teórico do leite desnatado a ser padronizado (em kg);

$\mathrm{g}_{\llcorner\llcorner}=$conteúdo de gordura esperado no leite após padronização (em \%);

$\mathrm{g}_{\text {。 }}=$ conteúdo de gordura medido no leite desnatado (em \%).

g. = conteúdo de gordura no leite integral (\%).

\section{4 - Elaboração do iogurte natural batido}

Cada tipo de leite (30L de cada tratamento) foi processado separadamente, em um único dia, utilizando-se os procedimentos descritos por SPREER [20] para a elaboração do iogurte natural batido. Para isto, o leite foi transferido para um recipiente de aço inox, sendo o mesmo acoplado à iogurteira onde foi aquecido a $90^{\circ} \mathrm{C}$ por 15 minutos e, em seguida, resfriado até $43^{\circ} \mathrm{C}$.

O cultivo lácteo utilizado (Visbyvac, Alemanha) continha as bactérias termofilicas Streptococcus thermophilus e Lactobacillus delbruekii ssp. bulgaricus. A cultura mãe foi preparada assepticamente através de semeadura do cultivo liofilizado em um litro de leite previamente aquecido $\left(90^{\circ} \mathrm{C}\right.$ por 30 minutos), seguido de incubação $\left(42^{\circ} \mathrm{C}\right.$ por três horas), até alcançar o valor de $\mathrm{pH}$ de $4,5-$ 4,65 . Esta cultura era mantida a $5 \mathrm{C}$, sendo utilizada para o preparo do cultivo starter no dia de produção do iogurte, através da semeadura de 2-3\% em um litro de leite nas mesmas condições descritas anteriormente, de maneira a conter cerca de $10^{\circ} \mathrm{UFC} / \mathrm{mL}$ [20]. Todos os procedimentos para o preparo e manutenção dos cultivos foram realizados em laboratório localizado fora da área de processamento dos iogurtes.

Para a produção do iogurte, adicionou-se o cultivo starter na proporção de $2 \%(\mathrm{v} / \mathrm{v})$ do leite contido na iogurteira, seguido de homogeneização e repouso para incubação a $43^{\circ} \mathrm{C}$ por aproximadamente 3 horas. Após este periodo, o produto foi resfriado até chegar a uma temperatura inferior a $20^{\circ} \mathrm{C}$, agitado manualmente com haste de aço inox durante 5 minutos e embalado em garrafas de polietileno com capacidade de $1.000 \mathrm{~mL}$.

A seqüência de fabricação descrita foi repetida 5 vezes, a cada 15 dias, totalizando 5 lotes de iogurte para cada tratamento estabelecido no experimento. Os iogurtes processados foram armazenados a $5^{\circ} \mathrm{C}$, por 30 dias. No $1^{\circ}$ dia após a fabricação, uma amostra/lote de iogurte foi analisada quanto à contagem de bactérias láticas, utilizando-se agar MRS [20], sendo que todos os tratamentos apresentaram contagens semelhantes, com média global de $6,8 \times 10^{\prime} \pm 1,2 \times 10^{\mathrm{UFC}} / \mathrm{mL}$. Foram colhidas duas 
amostras /lote do produto nos dias $1^{\circ}, 15^{\circ}$ e $30^{\circ}$, para a execução das análises físico-químicas e sensoriais.

\section{5 - Avaliação do iogurte natural batido}

\subsection{1 - Análises físico-químicas}

As análises físico-químicas nos iogurtes foram realizadas segundo a AOAC [2], compreendendo $\mathrm{pH}$, acidez e percentuais de gordura, proteina, ST (determinado através de método gravimétrico) e SNG (estimado pela diferença entre o EST e o percentual de gordura).

\subsection{2 - Viscosidade aparente}

As amostras destinadas à avaliação da viscosidade foram transportadas em caixas isotérmicas contendo gelo reciclável para proporcionar a permanência da temperatura próxima à temperatura de armazenagem em câmara fria. No laboratório, as amostras foram homogeneizadas, após o que, cerca de $500 \mathrm{~mL}$ foram vertidos em um Becker para a realização da análise.

A viscosidade aparente dos iogurtes foi determinada com um viscosímetro digital programável (Brookfield, modelo DV-II+), utilizando-se sonda cilíndrica $\mathrm{n}^{\circ} 4$ e velocidade de 50rpm [15] durante 20 minutos, a 9-11 ${ }^{\circ} \mathrm{C}$. Os resultados foram expressos em Centipoise (cP).

\subsection{3 - Análises sensoriais}

As amostras de iogurte de um dos lotes experimentais foram submetidas a um painel não treinado $[1,11]$ constituído por 85 provadores, recrutados entre alunos, professores e funcionários do campus da USP em Pirassununga. Os testes foram conduzidos em instalação própria para a avaliação sensorial de alimentos, pertencente ao Campus, em cabines individuais nas quais os provadores atribuíram valores aos produtos numa escala hedonística de 9 pontos para cada uma das seguintes características [20]: aspecto (peso 0,5); consistência (peso 1,0); odor (peso 0,5); e sabor (peso 2,0). O valor final de cada amostra correspondeu à média ponderada de pontos atribuídos pelos provadores para cada característica. As amostras foram submetidas ao painel em sua forma natural, sem acréscimo de outros ingredientes, a temperatura de cerca de $10^{\circ} \mathrm{C}$. O iogurte foi servido em copos de plástico incolor, em volumes de cerca de $70 \mathrm{~mL}$.

\section{6 - Análise estatística}

Os resultados obtidos nos exames laboratoriais foram submetidos à ANOVA, considerando 3 tratamentos (iogurte integral, padronizado a 3,0\% de gordura, e desnatado a $0,5 \%$ de gordura) e 5 repetições. Para a comparação entre as médias empregou-se o teste de Tukey, adotando-se $\alpha=0,05$ [8].

\section{3 - RESULTADOS E DISCUSSÃO}

\section{1 - Caracterização da matéria-prima}

Os resultados obtidos nas análises físico-químicas do leite bubalino in natura, utilizado na fabricação dos 5 lotes de iogurtes, encontram-se na Tabela 1. Os valores obtidos para todos os parâmetros apresentaram-se, de modo geral, dentro da normalidade esperada para o leite de búfala $[13,21]$.

TABELA 1 - Características físico-químicas do leite de búfala integral in natura

\begin{tabular}{lcccccc}
\hline & \multicolumn{7}{c}{ Lotes } \\
\hline Parâmetros & 1 & 2 & 3 & 4 & 5 & Média $^{1}$ \\
\hline Indice crioscópico ( $\left.{ }^{\circ} \mathrm{C}\right)$ & 0,533 & 0,535 & 0,535 & 0,531 & 0,536 & $0,534 \pm 0,002$ \\
Densidade (m/v, 15 $\left.{ }^{\circ} \mathrm{C}\right)$ & $1.032,6$ & $1.033,6$ & $1.034,0$ & $1.035,7$ & $1.033,3$ & $1.033,84 \pm 1,09$ \\
Acidez ( $\left.{ }^{\circ} \mathrm{D}\right)$ & 20,0 & 20,5 & 19,0 & 20,0 & 21,0 & $20,10 \pm 0,99$ \\
pH & 6,79 & 6,67 & 6,75 & 6,60 & 6,70 & $6,70 \pm 0,07$ \\
Gordura (\%) & 6,85 & 7,00 & 6,75 & 6,80 & 6,70 & $6,82 \pm 0,11$ \\
Proteina (\%) & 4,34 & 4,60 & 4,08 & 4,10 & 4,30 & $4,28 \pm 0,20$ \\
Sólidos totais (\%) & 16,93 & 17,59 & 17,15 & 18,12 & 16,92 & $17,34 \pm 0,49$ \\
Sólidos não-gordurosos (\%) & 10,07 & 10,39 & 10,40 & 10,92 & 10,22 & $10,40 \pm 0,30$ \\
\hline T'Resultados expressam a média \pm desvio padrão. & & & &
\end{tabular}

\section{2 - Caracteristicas físico-quimicas do iogurte}

A Tabela 2 apresenta os resultados das análises físico-químicas do iogurte nos dias 1,15 e 30 após a fabricação. Para o dia 1, os valores de acidez, $\mathrm{pH}$, proteína e SNG foram muito semelhantes nos iogurtes elaborados com os diferentes tipos de leite $(\mathrm{P}>0,05)$. Os percentuais de gordura e ST variaram de acordo com a padronização, ou seja, os valores foram similares aos respectivos teores no leite utilizado como matéria-prima.

Os resultados físico-químicos obtidos em todos os lotes de iogurte de leite de búfala estiveram de acordo com os parâmetros mínimos definidos na legislação brasileira para o produto conforme sua classificação em integral, padronizado e desnatado [4].

Relativamente ao comportamento das variáveis ao longo do período de estocagem, observou-se que a acidez aumentou em todos os produtos, ao passo que o $\mathrm{pH}$ diminuiu progressivamente durante o período de estocagem, embora sem efeito significativo $(P>0,05)$ entre os tratamentos. Os resultados demonstraram que a padronização do teor de gordura não interferiu com estes parâmetros, os quais estão associados, principalmente, à atividade biológica do cultivo lácteo empregado na fabricação do iogurte [20]. Os resultados encontrados para a acidez estão de acordo com os valores encontrados por YABU et al. [22] e SCHOLZ \& ANTUNES [17], para o iogurte elaborado com leite integral de búfala $(0,78 \%$ e $1,21 \%$, respectivamente). Contudo, CHAWLA \& BALACHANDRAN [5] observaram maior acidez e menores valores de $\mathrm{pH}$ à medida que o teor de SNG aumentou nos iogurtes de leite bubalino. No presente trabalho, não houve modificações significativas nos teores de proteína, gordura, SNG e ST ao longo do período de armazenagem. 
TABELA 2 - Características físico-químicas dos iogurtes produzidos com leite bubalino nos dias 1,15 , e 30 após a fabricação

\begin{tabular}{|c|c|c|c|c|c|c|}
\hline $\begin{array}{l}\text { Tipo de } \\
\text { iogurte }\end{array}$ & $\begin{array}{c}\text { Acidez } \\
(\%)^{2}\end{array}$ & $\mathrm{pH}$ & $\begin{array}{c}\text { Gordura } \\
(\%)\end{array}$ & $\begin{array}{c}\text { Proteína } \\
(\%)\end{array}$ & $\begin{array}{l}\mathrm{ST}^{3} \\
(\%)\end{array}$ & $\begin{array}{l}\mathrm{SNG}^{4} \\
(\%)\end{array}$ \\
\hline \multicolumn{7}{|l|}{ Dia 1: } \\
\hline Integral & $1,13 \pm 0,14^{*}$ & $4,41 \pm 0,23^{\circ}$ & $6,80 \pm 0,20^{\circ}$ & $4,68 \pm 0,34^{2}$ & $16,40 \pm 0,32^{2}$ & $9,60 \pm 0,35^{2}$ \\
\hline Padronizado & $1,17 \pm 0,22^{*}$ & $4,38 \pm 0,29^{\circ}$ & $3,12 \pm 0,27^{b}$ & $4,65 \pm 0,27$ & $13,17 \pm 0,25^{b}$ & $10,05 \pm 0,32^{a}$ \\
\hline Desnatado & $1,12 \pm 0,15^{2}$ & $4,39 \pm 0,27^{\circ}$ & $0,50 \pm 0,10^{e}$ & $4,17 \pm 0,16$ & $10,83 \pm 0,29^{e}$ & $10,33 \pm 0,20^{\mathrm{A}}$ \\
\hline \multicolumn{7}{|l|}{ Dia 15: } \\
\hline Integral & $1,17 \pm 0,07^{\circ}$ & $4,20 \pm 0,14^{2}$ & $6,80 \pm 0,32^{4}$ & $4,44 \pm 0,23^{2}$ & $16,40 \pm 0,26^{2}$ & $9,60 \pm 0,27^{2}$ \\
\hline Padronizado & $1,22 \pm 0,02^{*}$ & $4,18 \pm 0,09^{\circ}$ & $2,94 \pm 0,22^{b}$ & $4,54 \pm 0,15^{2}$ & $13,07 \pm 0,47^{b}$ & $10,13 \pm 0,49^{\circ}$ \\
\hline Desnatado & $1,21 \pm 0,07^{\circ}$ & $4,12 \pm 0,08^{\circ}$ & $0,48 \pm 0,08^{e}$ & $4,74 \pm 0,78^{\circ}$ & $10,81 \pm 0,35^{e}$ & $10,33 \pm 0,29^{\circ}$ \\
\hline \multicolumn{7}{|l|}{ Dia 30: } \\
\hline Integral & $1,23 \pm 0,22^{2}$ & $4,10 \pm 0,15^{a}$ & $6,92 \pm 0,18^{\circ}$ & $4,37 \pm 0,29^{\circ}$ & $16,32 \pm 0,37^{\circ}$ & $9,40 \pm 0,41^{2}$ \\
\hline Padronizado & $1,26 \pm 0,25^{n}$ & $4,07 \pm 0,07^{\circ}$ & $2,96 \pm 0,43^{b}$ & $4,52 \pm 0,39^{\circ}$ & $12,89 \pm 0,50^{b}$ & $10,03 \pm 0,5^{2}$ \\
\hline Desnatado & $1,24 \pm 0,23^{*}$ & $4,11 \pm 0,04^{2}$ & $0,50 \pm 0,07^{2}$ & $4,44 \pm 0,29^{\prime \prime}$ & $11,01 \pm 0,41^{\circ}$ & $10,51 \pm 0,37^{\circ}$ \\
\hline
\end{tabular}

\section{3 - Viscosidade aparente}

A viscosidade aparente obtida para os 3 tipos de iogurte nos dias 1, 15 e 30 encontra-se apresentada na Figura 1. Tendo em vista o comportamento tixotrópico típico de iogurte [3], observou-se uma queda da viscosidade aparente durante o tempo de análise. Por isso, e por se tratar de um fluído não newtoniano, considera-se que a propriedade estudada neste trabalho é a viscosidade aparente, cujos valores foram calculados da porção assintótica das respectivas curvas, isto é, da porção final dessas.

Assim, observou-se que no $1^{\mathrm{o}}$ dia, o iogurte padronizado diferenciou-se dos demais tipos por apresentar valores de viscosidade ligeiramente menores, de cerca de $35 \mathrm{cP}$. Inversamente, no $15^{\circ}$ dia, o iogurte padronizado apresentou maior viscosidade $(55 \mathrm{cP})$, seguido do desnatado $(54 \mathrm{cP})$ e do integral $(52 \mathrm{cP})$, mas no $30^{\circ}$ dia, os valores de viscosidade do iogurte integral foram maiores $(56 \mathrm{cP})$ do que o padronizado $(54 \mathrm{cP})$ e o desnatado $(53 \mathrm{cP})$, observando-se ainda que a viscosidade aparente de todos os iogurtes nos dias 15 e 30 foi ligeiramente maior que a do $1^{\mathrm{o}}$ dia. Este comportamento variado pode ser atribuído às diferenças na velocidade de multiplicação das bactérias do cultivo starter [10]. De qualquer modo, estas variações foram pequenas, não sendo constatadas diferenças significativas nos valores médios de viscosidade nos diferentes tratamentos nos dias 1,15 e 30 de amazenamento $(\mathrm{P}>0,05)$, o que permite considerar que a redução do teor de gordura do leite de búfala não influenciou a viscosidade do iogurte natural, diferentemente do que ocorre no iogurte produzido com leite bovino $[3,18]$. Este fato indica que a adição de leite em pó ou outro método de reforço do teor de ST no leite não é necessário para a manutenção das características físicas do iogurte produzido com leite desnatado de búfala.

Os valores da viscosidade aparente dos iogurtes de leite de búfala determinados neste trabalho são comparáveis aos valores determinados por SHAKER, JUMAH \& ABU-JDAYIL [18] com iogurtes de leite bovino com dife- rentes teores (0-3\%) de gordura (40-80cP) e por CHENG, CLARKE \& AUGUSTIN [6] com iogurtes elaborados com leite de vaca contendo 10 e $12 \%$ SNG (30-76cP).

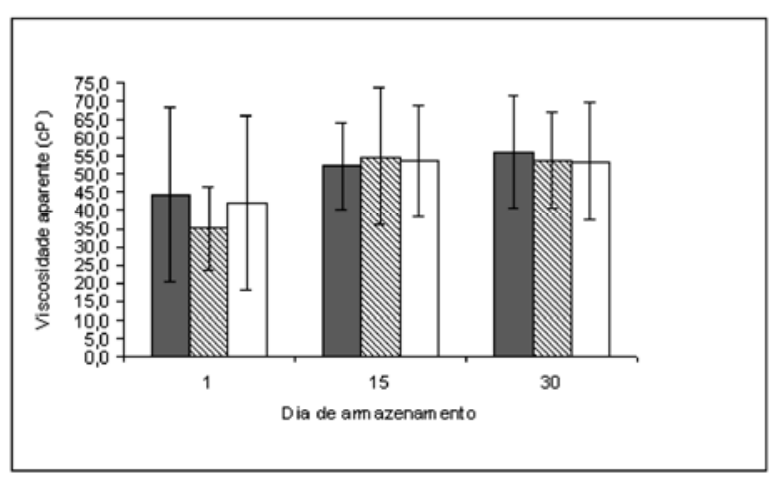

FIGURA 1. Viscosidade aparente (média dos valores das assintotas das curvas \pm desvio padrão, $n=5$ ) dos iogurtes durante $\mathrm{O}$ armazenamento por 30 dias a $5^{\circ} \mathrm{C}$. Q-Iogurte integral; $\square$-Iogurte padronizado; $\square$-Iogurte desnatado

\section{4 - Caracteristicas sensoriais}

$\mathrm{Na}$ Tabela 3 estão apresentados os resultados obtidos na análise sensorial do iogurte nos dias 1, 15 e 30. No $1^{\circ}$ dia de avaliação, todos os atributos avaliados apresentaram valores semelhantes para os 3 tipos de iogurte, com exceção da consistência do produto, cuja nota foi maior $(\mathrm{P}<0,05)$ para o iogurte desnatado. Apesar disso, não houve diferenças significativas na nota final ponderada dos iogurtes. Além disso, não houve diferença $(\mathrm{P}>$ $0,05)$ nas notas atribuídas à consistência do iogurte nas avaliações dos dias 15 e 30, o que está em concordância com os resultados de viscosidade aparente obtidos no presente trabalho.

Nas avaliações dos dias 15 e 30, os valores atribuídos ao sabor dos iogurtes desnatado e integral foram menores ao do produto padronizado, embora a diferença tenha sido significativa $(\mathrm{P}<0,05)$ somente com relação ao iogurte desnatado. Similarmente, as notas finais de aceitação do iogurte padronizado foram maiores do que os outros tipos, porém, as diferenças não foram significativas. Este resultado é coerente com os dados obtidos por CHAWLA \& BALACHANDRAN [5], os quais observaram melhores resultados na avaliação sensorial do iogurte produzido com leite bubalino contendo 3,0\% de gordura e $10 \%$ de SNG.

As médias relativas ao aspecto e ao odor dos produtos não sofreram variações pronunciadas ao longo do período de estocagem, e também não apresentaram diferenças significativas $(P>0,05)$ nas avaliações.

Em sintese, pode-se afirmar que todos os iogurtes produzidos no experimento foram adequados ao consumo. Contudo, o iogurte produzido com leite padronizado apresentou maior estabilidade do que os demais tipos, uma vez que as notas de aceitação mantiveram-se relativamente constantes após 15 e 30 dias. Deve-se ressaltar, 
também, que esta preferência dos avaliadores, ligeiramente maior para o produto padronizado (gordura $=$ $3,0 \%$, pode ser devida, entre outros fatores, à similaridade da composição deste com o iogurte integral batido elaborado com leite bovino.

O leite bubalino, por apresentar maiores concentrações de gordura e proteínas, confere características sensoriais peculiares aos derivados lácteos, o que permite a obtenção de produtos, como o iogurte, com propriedades diferentes das observadas do iogurte elaborado com o leite da espécie bovina. A avaliação sensorial realizada no presente experimento demonstrou que o iogurte produzido exclusivamente com leite de búfala apresenta um bom potencial para o consumo em nossas condições.

TABELA 3 - Notas da análise sensorial dos iogurtes produzidos com leite bubalino nos dias 1, 15, e 30 após a fabricação

\begin{tabular}{|c|c|c|c|c|c|}
\hline Tipo de iogurte & Aspecto & Consistência & Odor & Sabor & Nota Final $^{2}$ \\
\hline \multicolumn{6}{|l|}{$\overline{\text { Dia I: }}$} \\
\hline Integral & $7,4 \pm 1,6^{\mathrm{a}}$ & $7,1 \pm 1,6^{\mathrm{a}}$ & $7,3 \pm 1,7^{\mathrm{a}}$ & $6,5 \pm 2,0^{n}$ & $6,9 \pm 1,6^{\mathrm{a}}$ \\
\hline Padronizado & $7,7 \pm 1,3^{\mathrm{n}}$ & $7,4 \pm 1,3^{\mathrm{a}}$ & $6,9 \pm 1,6^{a}$ & $6,4 \pm 1,9^{n}$ & $6,9 \pm 1,3^{a}$ \\
\hline Desnatado & $7,6 \pm 1,3^{\mathrm{a}}$ & $7,6 \pm 1,1^{b}$ & $7,0 \pm 1,5^{\mathrm{a}}$ & $6,3 \pm 1,8^{n}$ & $6,9 \pm 1,2^{n}$ \\
\hline \multicolumn{6}{|l|}{ Dia 15: } \\
\hline Integral & $7,7 \pm 1,2^{\mathrm{a}}$ & $7,1 \pm 1,5^{n}$ & $7,1 \pm 1,6^{a}$ & $6,1 \pm 2,2^{\mathrm{ab}}$ & $6,7 \pm 1,5^{a}$ \\
\hline Padronizado & $7,7 \pm 1,3^{\mathrm{a}}$ & $7,0 \pm 1,7^{a}$ & $6,9 \pm 1,6^{\mathrm{a}}$ & $6,4 \pm 1,9^{n}$ & $6,8 \pm 1,3^{\mathrm{a}}$ \\
\hline Desnatado & $7,6 \pm 1,5^{\mathrm{a}}$ & $7,0 \pm 1,6^{4}$ & $6,9 \pm 1,6^{a}$ & $5,6 \pm 2,1^{b}$ & $6,4 \pm 1,5^{a}$ \\
\hline \multicolumn{6}{|l|}{ Dia 30: } \\
\hline Integral & $7,8 \pm 1,4^{\mathrm{a}}$ & $7,1 \pm 1,7^{a}$ & $7,4 \pm 1,7^{a}$ & $5,5 \pm 2,0^{\circ b}$ & $6,4 \pm 1,4^{a}$ \\
\hline Padronizado & $7,7 \pm 1,1^{a}$ & $7,0 \pm 1,5^{a}$ & $6,9 \pm 1,4^{a}$ & $6,7 \pm 2,1^{\star}$ & $6,9 \pm 1,2^{a}$ \\
\hline Desnatado & $7,7 \pm 1,3^{\mathrm{a}}$ & $7,5 \pm 1,0^{*}$ & $7,3 \pm 1,4^{a}$ & $5,3 \pm 2,0^{b}$ & $6,4 \pm 1,0^{a}$ \\
\hline \multicolumn{6}{|c|}{$\begin{array}{l}\text { Resultados expressam a média } \pm \text { desvio padrão de notas atribuidas por } 85 \\
\text { provadores; } \\
\text { 2Nota final calculada com base na ponderacăo das notas individuais de cada } \\
\text { atributo (aspecto e odor: peso 0,5; consisténcia: peso } 1 \text {; sabor: peso 2). } \\
\text { a,be Em uma coluna, médias seguidas de letras desiguais diferem estatisticamente } \\
(\text { (P }<0,05) \text {. }\end{array}$} \\
\hline & & - $\mathrm{COI}$ & US & & \\
\hline
\end{tabular}

Face aos resultados obtidos no presente experimento, pode-se concluir que:

- os iogurtes produzidos com leite bubalino integral, padronizado e desnatado apresentaram valores de acide $\mathrm{e}$ pH semelhantes durante 30 dias de armazenamento a $5^{\circ} \mathrm{C}$;

- os valores de viscosidade aparente dos iogurtes padronizado e desnatado não mostraram diferenças com o produto integral, apesar de terem aumentado ligeiramente após o $1^{\circ}$ dia;

- o iogurte produzido com leite padronizado a 3,0\% de gordura apresentou melhor sabor em relação ao iogurte desnatado;

- os atributos aspecto, consistência e odor dos iogurtes não apresentaram diferenças entre os 3 tipos de iogurte;
- $\quad$ o iogurte de leite de búfala, principalmente o produto contendo 3,0\% de gordura, apresentou maior estabilidade nas avaliações sensoriais realizadas após 1 , 15 e 30 dias de armazenamento a $5^{\circ} \mathrm{C}$.

\section{5 - REFERÊNCIAS BIBLIOGRÁFICAS}

[1] AMERINE, M. A.; PANGBORN, R. M.; ROESSLER, E. M. A Principle of Sensory Evaluation of Foods. New York: Academic Press, 1967.

[2] AOAC (Association of Official Analytical Chemists). Official Methods of Analysis. 16. ed. Arlington: AOAC, 1995.

[3] BENEZECH, T.; MAINGONNAT, J. F. Characterization of rheological properties of yogurt. A review. J. Food Eng., v. 21, n. 4, p. 447-472, 1994.

[4] BRASIL. Leis, decretos, etc. Portaria N 146 do Ministério da Agricultura, Abastecimento e da Reforma Agrária. Diário Oficial, Brasília, 07 mar. 1996. Aprova os Regulamentos Técnicos de Identidade e Qualidade dos Produtos Lácteos.

[5] CHAWLA, A. K.; BALACHANDRAN, R. Studies on yoghurt buffalo milk: effect on different solids not fat content on chemical, rheological and sensory characteristics. Indian J. Dairy Sci., v. 47, p. 762-765, 1994.

[6] CHENG, L. J.; CLARK, P. T.; AUGUSTIN, M. A. Seasonal variation in yogurt properties. Australian Journal of Dairy Technology, v.57, p. 187-191, 2002.

[7] FERRARA, B.; INTRIERI, F. Características e emprego do leite de búfala. Zootecnia, v. 13, n. 1, p. 25-50, 1975.

[8] GACULA, J. R.; SINGH, J. Statistical Methods in Food and Consumer Research. Orlando: Academic Press, 1984.

[9] GANGULI, N. C. Buffalo milk technology. Revista Mundial de Zootecnia, v. 30, p. 2-10, 1979.

[10] GASSEM, M. A., FRANK, J. F. Physical properties of yogurt made from milk treated with proteolitic enzymes. Journal of Dairy Science, v.74, p. 1503-1511, 1991.

[11] INSTITUT OF FOOD TECHNOLOGISTS. Sensory evaluation guide for testing food and beverage products. Food Technol., v. 35, p. 50-59, 1981.

[12] IYENGAR, M. K. K.; NAMBUDRIPAD, V. K. N; DUDANI, A. T. Effect of heat-treatment of buffalo and cow milk in the manufacture of yoghurt. Indian J. Dairy Sci., v. 20, p. 810, 1967.

[13] NADER FILHO, A.; AMARAL, L. A.; TONHATI, H.; PENHA, L. H. C.; TOLEDO, L. M. Variação das características físico-químicas do leite de búfala, durante os diferentes meses do período de lactação. Artigos de Veterinária, v. 12 , p. $148-153,1996$

[14] NASCimento, C.; CARVAlHo, C. O. M. Criação de búfalos. Brasília: EMBRAPA, 1993.

[15] PELEGRINE, D. H.; VIDAL, J. R. M. B.; GASPARETTO, C. A. Estudo da viscosidade aparente das polpas de manga (Keitt) e abacaxi (Pérola). Ciênc. Tecnol. Aliment., v. 20, p. $128-131,2000$.

[16] QUEIROZ, L. S. O.; LOURENÇO JÚNIOR, J. B.; SOUZA, C. Avaliação microbiológica de iogurte de leite de búfala, com sabor de frutas da Amazônia, para a merenda 
escolar. Higiene Alimentar, v. 16, p. 39-44, 2002.

[17] SCHOlZ, M. B.; ANTUNES, L. A. F. Aproveitamento da mistura de leite de vaca e de búfala para a produção de iogurte. I. Aspectos Físico-químicos e microbiológicos. Revista do Instituto de Laticinios Cândido Tostes, v. 50, p. 30-46, 1996

[18] SHAKER, R. R.; JUMAH, R.Y.; ABU-JDAYIL. Rheological properties of plain yogurt during coagulation process: impact of fat content and preheat of milk. J. Food Eng., v. 44, p. 175-180, 2000.

[19] SOUZA, G. Iogurte: tecnologia, consumo e produção em alta. Leite e Derivados, n. 28, p. 44-54, 1996.

[20] SPREER, E. Lactologia Industrial. 2. ed. Zaragoza: Acribia, 1991.
[21] VERRUMA, M. R.; SALGADO, J. M. Avaliação nutricional do leite de búfala em comparação ao leite de vaca. Scientia Agrícola, v. 51, p. 131-137, 1994.

[22] YABU, M. C.; SCHOLZ, M. B. S.; RAPACCI, M.; ANTUNES, L. A. F. Caracteristicas físico-químicas e sensoriais de iogurte produzido de misturas de leite bovino e bubalino. Revista do Instituto de Laticinios Cândido Tostes, v. 43, p. 35-37, 1988.

\section{6 - AGRADECIMENTOS}

Os autores agradecem à Fundação de Amparo à Pesquisa do Estado de São Paulo (FAPESP) pelo auxílio financeiro. 